\title{
Measuring fluorine in uranium oxyfluoride particles using secondary ion mass spectrometry for nuclear forensics
}

\author{
By R. Kips ${ }^{1, *}$, M. J. Kristo ${ }^{1}$, I. D. Hutcheon ${ }^{1}$, Z. Wang ${ }^{2}$, T. J. Johnson ${ }^{2}$, D. C. Gerlach ${ }^{2}$, J. E. Amonette ${ }^{2}$, K. B. Olsen ${ }^{2}$ and \\ E. Stefaniak ${ }^{3}$ \\ ${ }^{1}$ Lawrence Livermore National Laboratory, Glenn T. Seaborg Institute, P.O. Box 808, L-231, Livermore, CA 94551, USA \\ 2 Pacific Northwest National Laboratory, P.O. Box 999, Richland, WA 99352, USA \\ ${ }^{3}$ European Commission, Joint Research Centre, Institute for Reference Materials and Measurements, Retieseweg 111, 2440 Geel, Belgium
}

(Received December 23, 2009; accepted in revised form December 22, 2010)

\begin{abstract}
Secondary ion mass spectrometry /
Uranium oxyfluoride particles / Nuclear forensics /

Scanning electron microscopy
\end{abstract}

\begin{abstract}
Summary. Gaseous uranium hexafluoride $\left(\mathrm{UF}_{6}\right)$ is used for the enrichment of uranium and is known to be a very reactive and volatile gas. When a small amount of $\mathrm{UF}_{6}$ is released in the environment, it forms uranium oxyfluoride $\left(\mathrm{UO}_{2} \mathrm{~F}_{2}\right)$ particles and hydrogen fluoride from the reaction with atmospheric moisture. The $\mathrm{UO}_{2} \mathrm{~F}_{2}$ particles settle on various surfaces within the enrichment facility where they are collected by safeguards organizations such as the International Atomic Energy Agency (IAEA) through a technique called environmental sampling. Despite their small size, the uranium isotopic composition of these particles is used to determine whether an enrichment facility is compliant with its declarations. Additional and complementary information on the particles' source, formation process and exposure history can be obtained from elemental, molecular and morphological analysis. As fluorine is not always detected in uranium particles originating from enrichment facilities, it is assumed that $\mathrm{UO}_{2} \mathrm{~F}_{2}$ is unstable under certain environmental conditions. This study aims to determine how those environmental conditions affect the relative amount of fluorine in $\mathrm{UO}_{2} \mathrm{~F}_{2}$ particles. Expressly for the purpose of this work, we prepared a set of $\mathrm{UO}_{2} \mathrm{~F}_{2}$ particle samples from the hydrolysis of $\mathrm{UF}_{6}$ and stored these samples in environmental chambers at different temperature, humidity and lighting conditions. The NanoSIMS secondary ion mass spectrometer, with a nanometer-scale spatial resolution, was used to measure the $\mathrm{F}^{+} / \mathrm{U}^{+}$secondary ion ratio of individual particles immediately after sample preparation, and at different time intervals. NanoSIMS analyses on single particles stored up to 7 months in dry air did not detect a significant decrease in the relative amount of fluorine. The exposure to high humidity however, resulted in a much lower $\mathrm{F}^{+} / \mathrm{U}^{+}$ratio, up to 2 orders of magnitude below that of the particles stored in dry air. It should be noted that fluorine was still detected in these samples, even after 7 months of high humidity exposure.
\end{abstract}

\section{Introduction}

Nuclear forensics relies on the analysis of certain sample characteristics to determine the origin and history of a nu-

\footnotetext{
*Author for correspondence (E-mail: kips1@llnl.gov).
}

clear material. In the specific case of uranium enrichment facilities, it is the release of trace amounts of uranium hexafluoride $\left(\mathrm{UF}_{6}\right)$ gas - used for the enrichment of uranium - that leaves a process-specific fingerprint. When this $\mathrm{UF}_{6}$ gas interacts with atmospheric moisture, uranium oxyfluoride $\left(\mathrm{UO}_{2} \mathrm{~F}_{2}\right)$ particles or particle agglomerates are formed with sizes ranging from several microns down to a few tens of nanometers [1]. These particles are routinely collected and analyzed by safeguards organizations, such as the International Atomic Energy Agency (IAEA), where the uranium particulate material is measured for its isotopic composition. The range of uranium isotopic compositions that result from these measurements are compared to the facilities' declarations, allowing them to verify whether a facility is compliant with its declarations [2-4].

Since fluorine is not always detected in uranium particles originating from enrichment facilities, it is assumed that $\mathrm{UO}_{2} \mathrm{~F}_{2}$ is unstable under certain environmental conditions [5]. This study aims to determine whether the relative amount of fluorine in individual $\mathrm{UO}_{2} \mathrm{~F}_{2}$ particles can be correlated to those exposure conditions. A better understanding of the rate of fluorine loss in $\mathrm{UO}_{2} \mathrm{~F}_{2}$ particles, and the parameters that control it, may contribute to placing boundaries on the particle's exposure time in the environment.

Expressly for the purpose of this study, we prepared a set of $\mathrm{UO}_{2} \mathrm{~F}_{2}$ particles from a static release of $\mathrm{UF}_{6}$ in a humid atmosphere, and stored the majority of the samples in environmental chambers with controlled temperature, humidity and light conditions. Individual particles or particle agglomerates from these samples were characterized by secondary ion mass spectrometry with nanometer-scale spatial resolution (NanoSIMS). The relative amount of fluorine was determined at different stages in the aging process, as well as immediately after preparation (baseline measurement).

\section{Experimental}

\subsection{Uranium oxyfluoride particle samples}

The uranium oxyfluoride particles used for this study were prepared at the Institute for Reference Materials and Measurements of the European Commission (EC-IRMM) in Belgium $[6,7]$. In a 21 static air volume, with a relative humidity 
Table 1. Overview of the temperature, relative humidity and light settings for the 4 environmental chambers used for particle storage at LLNL. The conditions for chambers ETS1 and ThF2 were changed to more moderate temperature and humidity levels (right column) after the first experiment (left column) was finished.

\begin{tabular}{lcccccc}
\hline & \multicolumn{2}{c}{ ETS 1 } & ETS 2 & ThF1 & \multicolumn{2}{c}{ ThF2 } \\
\hline Temperature $\left({ }^{\circ} \mathrm{C}\right)$ & 24 & 25 & 40 & 25 & 41 & 30 \\
Rel. humidity $(\%)$ & $<15$ & 30 & $<15$ & 76 & 77 & 43 \\
Light & $\begin{array}{c}\text { Simulated } \\
\text { daylight/dark }\end{array}$ & $\begin{array}{c}\text { Diffuse/ } \\
\text { dark }\end{array}$ & Diffuse & Diffuse \\
\hline
\end{tabular}

of around $70 \%$, an estimated $40 \mathrm{mg}$ of $\mathrm{UF}_{6}$ was released from a glass vial broken by a metallic pin, allowing the $\mathrm{UF}_{6}$ released from the vial to fully react with the atmospheric moisture. Upon release, the $\mathrm{UF}_{6}$ was almost immediately hydrolyzed to form $\mathrm{UO}_{2} \mathrm{~F}_{2}$ particles and hydrogen fluoride gas (HF) (Eq. (1)).

$$
\mathrm{UF}_{6}+2 \mathrm{H}_{2} \mathrm{O} \rightarrow \mathrm{UO}_{2} \mathrm{~F}_{2}+4 \mathrm{HF}
$$

$\mathrm{UF}_{6}$ slightly depleted in the ${ }^{235} \mathrm{U}$ isotope $(0.704 \%)$ was used for all particle samples. Graphite substrates (Grade A 3/8 inch polished carbon planchets, Ernest F. Fullam, New York) were placed at the bottom of the chamber to collect the particulate material through gravitational settling. The particle size ranged between a few hundred nanometers up to $1 \mu \mathrm{m}$. 174 particle samples were prepared at the IRMM and sent to Lawrence Livermore National Laboratory (LLNL) for either storage in environmental chambers at specific humidity, temperature and light exposure levels (Table 1), or immediate analysis by NanoSIMS (baseline measurement). The daylight simulating lamp used in environmental chamber 1 (ETS 1) was a full spectrum fluorescent lamp designed to simulate the spectrum of natural sunlight, with a $2 \%$ UV-B component (Arcadia FSU18, 18W, 900 lm, 5600 K).

\subsection{Secondary ion mass spectrometry (SIMS)}

The Cameca NanoSIMS 50 secondary ion mass spectrometer at LLNL is able to measure the elemental composition of individual $\mathrm{UO}_{2} \mathrm{~F}_{2}$ particles. NanoSIMS is a destructive technique in which a $16 \mathrm{keV}$ beam of either $\mathrm{O}^{-}$(from a duo-plasmatron) or $\mathrm{Cs}^{+}$ions is rastered onto the sample, generating secondary ions that are detected by a doublefocusing mass spectrometer (Fig. 1). The combination of a short working distance, normal ion beam incidence and high brightness ion source results in a lateral resolution in the order of a few hundred nanometers. Up to 5 ion species can be detected simultaneously, spanning a mass difference of up to a factor 12 through an array of secondary electron multipliers. The large mass difference between fluorine $(m / z=19)$ and uranium oxide $(m / z=254)$ however, did require changing the magnetic field setting (peak jumping). A bulk $\mathrm{UF}_{4}$ sample was used for mass calibration. Variations in the ion intensities with sputtering were monitored by collecting $6 \mu \mathrm{m} \times 6 \mu \mathrm{m}$ ion images, while cycling the magnetic field to obtain a depth profile. Specific imageprocessing software (L'Image, Larry Nittler) was used for data reduction.

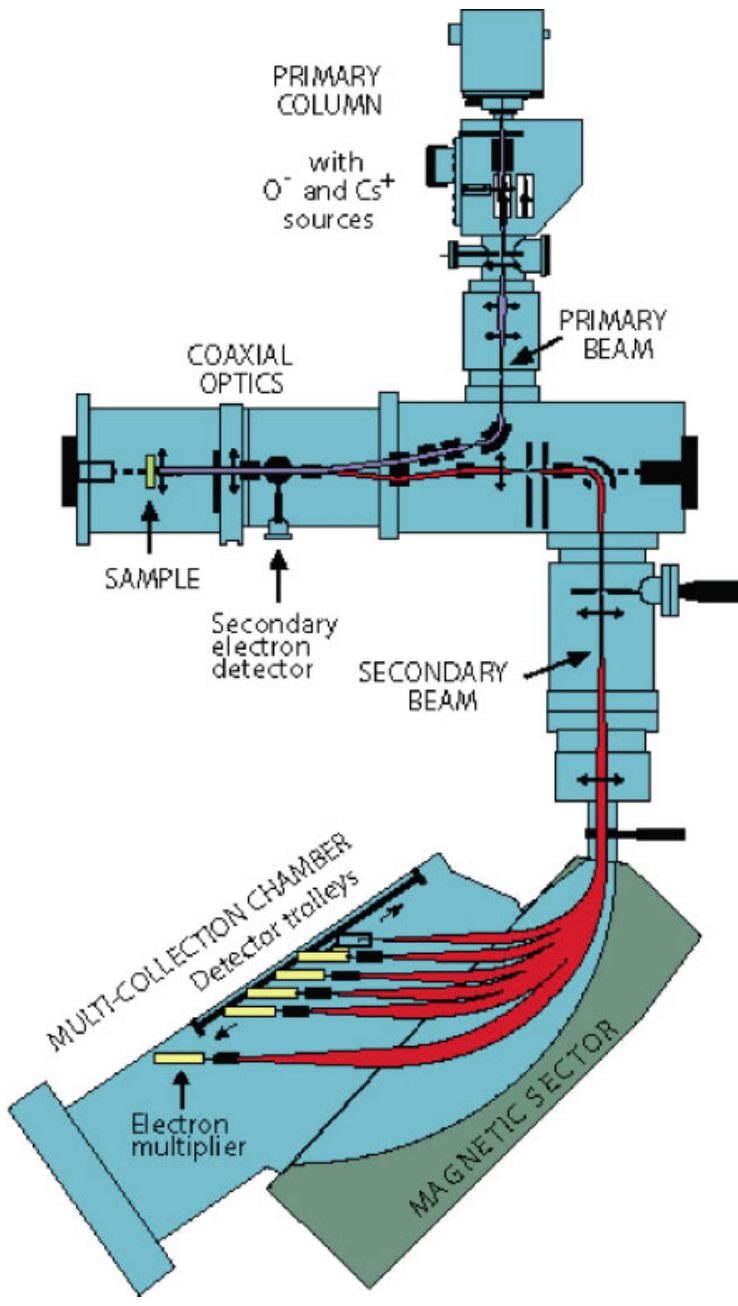

Fig. 1. Schematic of the Cameca NanoSIMS 50 secondary ion mass spectrometer.

\subsection{Scanning electron microscopy (SEM)}

Although NanoSIMS is a very powerful tool for the analysis of individual particles, sample characterization using scanning electron microscopy (SEM) remains indispensable. At the IRMM, a tungsten filament FEI Quanta 200 3D SEM was used to examine the particle loading and morphology before shipment to LLNL. This instrument has a spatial resolution of $3.5 \mathrm{~nm}$ at $20 \mathrm{kV}$ at a working distance of $8 \mathrm{~mm}$. An FEI Inspect F field-emission type SEM equipped with an EDAX Si(Li) detector was used at LLNL to monitor particle morphology and composition during storage in the environmental chambers.

\section{Results and discussion}

The analysis of the relative amount of fluorine in submicronsized particles requires the use of highly sensitive and selective instrumentation. The Cameca NanoSIMS 50 has the unique capability of sampling 3-6 atomic mono-layers in depth at any given time, with nanometer-scale spatial resolution. The measurement of $\mathrm{UO}_{2} \mathrm{~F}_{2}$ particles presents a number of additional challenges to this technique, however. In order to quantify the amount of fluorine in a single particle, the fluorine secondary ion intensity should be com- 


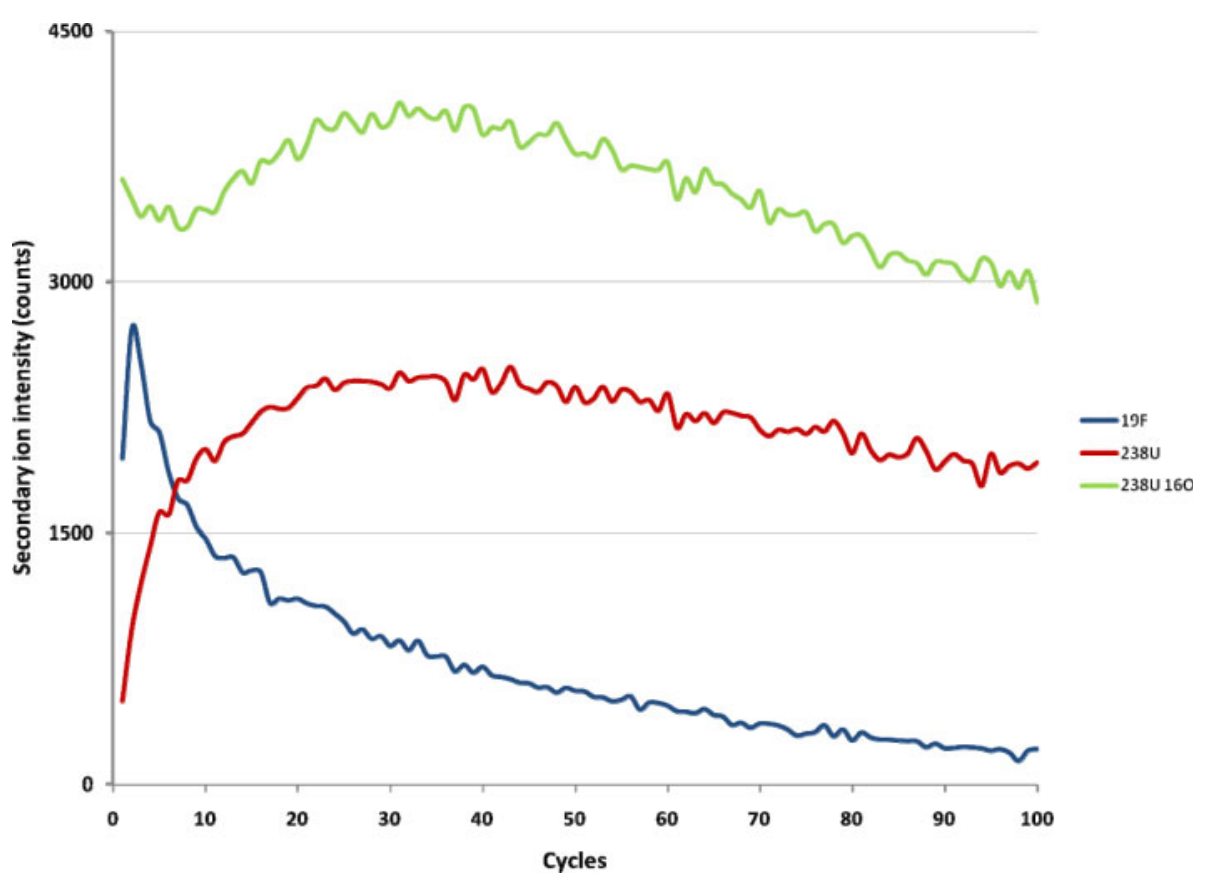

Fig. 2. Depth profile of a uranium oxyfluoride particle stored in an argon atmosphere for 2 months. The $\mathrm{F}^{+}, \mathrm{U}^{+}$and $\mathrm{UO}^{+}$secondary ion intensities were obtained by sputtering the particle with a $\mathrm{O}^{-}$primary ion beam. This depth profile was collected in approximately $1 \mathrm{~h}$. pared to the intensity of an ion characteristic of the uranium oxide matrix, preferably atomic uranium ions. For the generation of secondary ions we can either use a duoplasmatron $\left(\mathrm{O}^{-}\right.$primary ions) or a $\mathrm{Cs}^{+}$primary ion source. A primary beam of $\mathrm{O}^{-}$ions is typically used to chemically enhance the production of electropositive secondary ions, such as $\mathrm{U}^{+}$, whereas bombardment using $\mathrm{Cs}^{+}$primary ions stimulates the generation of electronegative secondary ions, including $\mathrm{F}^{-}$. The choice of primary ions will therefore always imply a less than optimal secondary ion yield for one of the ion species. Although the use of $\mathrm{Cs}^{+}$primary ions produces ion images with a spatial resolution of $100 \mathrm{~nm}$ (compared to $200-300 \mathrm{~nm}$ for $\mathrm{O}^{-}$primary ions) and has the additional advantage of producing secondary electron images during sputtering, the difference in count rate between the $\mathrm{U}^{-}$and $\mathrm{F}^{-}$ions was too large. For a freshly-prepared particle sample that was measured with a $\mathrm{Cs}^{+}$primary ion current of $1.8 \mathrm{pA}$, the $\mathrm{F}^{-}$count rate nearly reached the secondary electron multipliers operation limits, while the count rate for $\mathrm{U}^{-}$did not exceed more than 100 counts per second (cps). The primary ion beam source was therefore switched from $\mathrm{Cs}^{+}$to $\mathrm{O}^{-}$, and all further measurements described in this paper were carried out using the $\mathrm{O}^{-}$primary beam. With a primary current of approximately $80 \mathrm{pA}$, the secondary ion yield for the $\mathrm{U}^{+}$ ions was a few ten thousand cps, while the $\mathrm{F}^{+}$count rate was still as high as a few thousand cps (at the start of the analysis). Real-time imaging of the $\mathrm{UO}^{+}$secondary ions on a larger area, typically $30 \mu \mathrm{m} \times 30 \mu \mathrm{m}$, was used to locate and center the uranium particles for analysis. The beam was calculated to have a spot size of 300-400 nm. The raster size for the analysis was set to $6 \mu \mathrm{m} \times 6 \mu \mathrm{m}$, with an image resolution of $32 \times 32$ pixels. This was calculated to be sufficient for a 300-400 nm spot size and a 30\% overlap.

The ion species collected per cycle were limited to $\mathrm{F}^{+}$, $\mathrm{U}^{+}$and $\mathrm{UO}^{+}$to minimize the cycle time and maximize the number of data points during particle sputtering. An energy scan (secondary ion intensity as a function of sample voltage) was performed for each of the ion species and showed that they were well-aligned and centered. Depth profiles for the $\mathrm{F}^{+}, \mathrm{U}^{+}$and $\mathrm{UO}^{+}$ions were collected while changing the magnetic field of the mass analyzer for each of these ions in a series of cycles (peak jumping). The overall change in magnetic field was limited to less than $25 \%$. As a result, the magnetic hysteresis was found to be negligible and the peak position did not shift significantly during depth profiling. The depth profile for a sample stored in an argon atmosphere for 2 months since its preparation at IRMM, is shown in Fig. 2. Storage in an inert atmosphere is assumed to preserve the particle's chemical composition [8]. The total counts for $\mathrm{F}^{+}, \mathrm{U}^{+}$and $\mathrm{UO}^{+}$integrated over the $6 \mu \mathrm{m} \times 6 \mu \mathrm{m}$ raster were plotted against the cycle number. This analysis was stopped after the count rate of $\mathrm{F}^{+}$was reduced to background. Angular and energy aberrations were corrected for through the use of an entrance and aperture slit and flattop peaks were obtained for the uranium species at a mass resolving power of around 5000. At these measurement conditions, the transmission (secondary ion intensity reduction after insertion of the entrance slit) and conversion (percent secondary ions produced per primary ion) for $\mathrm{Al}^{+}$on an $\mathrm{Al}-$ $\mathrm{Cu}$ grid was around $60 \%$ and $2 \%$, respectively.

The $\mathrm{UO}^{+}$ions were generally the most abundant at the start of each measurement and varied around a few thousand cps. The $\mathrm{U}^{+}$ions tracked the $\mathrm{UO}^{+}$ratio as soon as the surface became implanted with oxygen. This point in the analysis is also referred to as sputtering equilibrium and occurred around cycle 25 in the depth profile of Fig. 2. The particle was estimated to be eroded at a rate of approximately $1 \mathrm{~nm} / \mathrm{s}$, resulting in a steady decrease of $\mathrm{U}^{+}$as sputtering of the particle progressed. The intensity of the uranium ions was still high at the end of the analysis, indicating that we did not completely sputter through the particle. The $\mathrm{F}^{+}$ secondary ion intensity did reach background values after 100 cycles. In contrast to the $\mathrm{U}^{+}$and $\mathrm{UO}^{+}$ions, the depth profile for $\mathrm{F}^{+}$in freshly-prepared $\mathrm{UO}_{2} \mathrm{~F}_{2}$ particles showed a sharp peak in the first few minutes of sputtering, followed by a steady decrease to background values. The secondary 


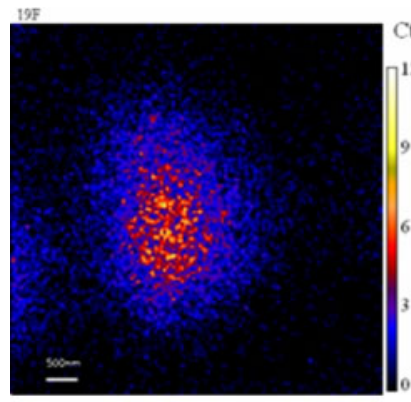

(a)

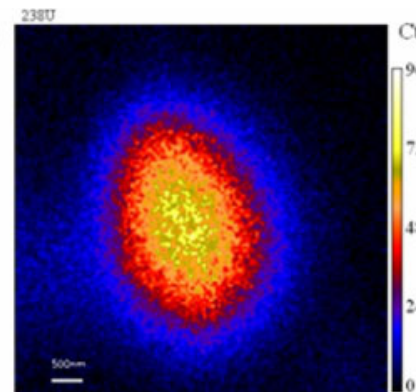

(b)

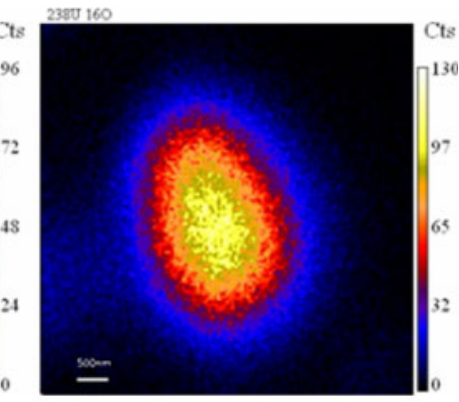

(c)

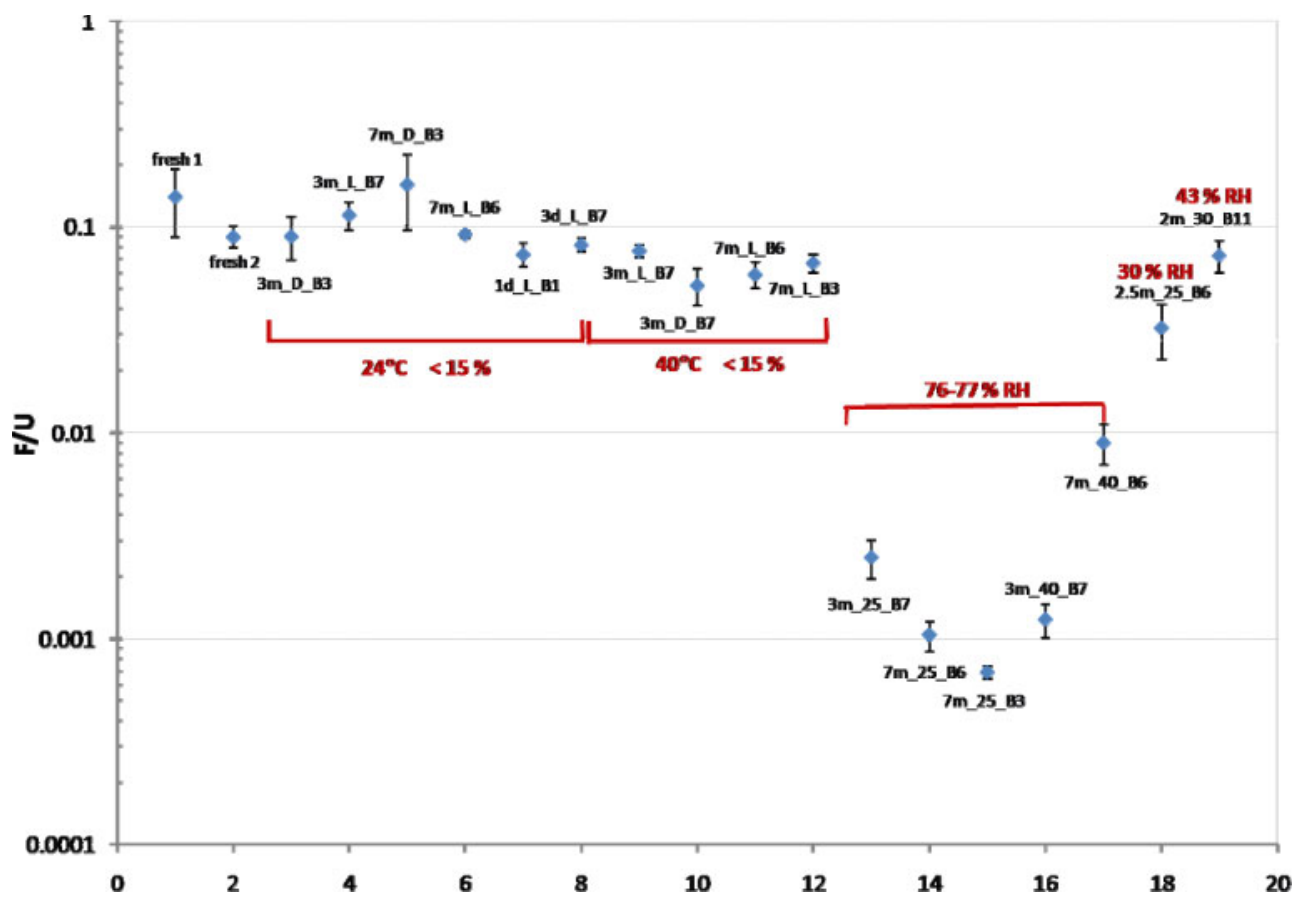

Fig. 3. $6 \mu \mathrm{m} \times 6 \mu \mathrm{m}$ ion images of $\mathrm{F}^{+}$(left), $\mathrm{U}^{+}$(middle) and $\mathrm{UO}^{+}$(right) from a uranium oxyfluoride particle measured by NanoSIMS. The scaling represents the variation in ion intensity throughout the raster, the scale bar in the left corner of each ion image represents $500 \mathrm{~nm}$. The ion images seem to indicate that fluorine is concentrated in the center of the particle.

Fig. 4. Overview of the $\mathrm{F}^{+} / \mathrm{U}^{+}$ ratios of 19 uranium oxyfluoride particle samples measured by NanoSIMS using $\mathrm{O}^{-}$primary ion bombardment.

ion images show that the $\mathrm{F}^{+}$ions were concentrated in the center of the particle (Fig. 3). The reason for this difference between the depth profiles of $\mathrm{F}^{+}$on the one hand, and those of $\mathrm{U}^{+}$and $\mathrm{UO}^{+}$on the other, is still not clear, but seems to suggest the loss of fluorine might be a 2-step process, with fluorine present in more than one form $\left(\mathrm{UO}_{2} \mathrm{~F}_{2} v s\right.$. HF or $\mathrm{UF}_{6}$ complexes). Planned experiments using micro-Raman spectroscopy will help determine how the fluorine is bound to the particles.

In order to evaluate the relative amount of fluorine in single particles, the total number of counts collected for $\mathrm{F}^{+}$was ratioed to the total number of counts for $\mathrm{U}^{+}$. The resulting $\mathrm{F}^{+} / \mathrm{U}^{+}$ratio provided a means to compare differences in composition between particles from the same sample and between samples that were stored under different environmental conditions. Measurements on particle samples carried out immediately after preparation indicated that a certain variation already exists within 2-3 weeks after preparation. The average $\mathrm{F}^{+} / \mathrm{U}^{+}$ratio calculated for two freshlyprepared samples obtained from 7 particle measurements each resulted in a ratio of $0.14 \pm 0.05$ and $0.09 \pm 0.01$, respectively. Even though differences in particle morphology, topography or charging of the sample may have affected the relative secondary ion yield and caused this variation, it could also be sample related, and a certain spread in the relative amount of fluorine may be inherent to the particle formation process.

Comparison of the average $\mathrm{F}^{+} / \mathrm{U}^{+}$ratio for these freshlyprepared samples to those of a set of samples stored under different humidity, temperature and lighting conditions did show variations in the $\mathrm{F}^{+} / \mathrm{U}^{+}$ratio beyond the within sample variability. An overview is presented in Fig. 4 (log scale). The sample labels indicate the time in the environmental chamber ( $7 \mathrm{~m}=7$ months, $3 \mathrm{~m}=3$ months, $1 \mathrm{~d}=1$ day, etc.), while the letter $\mathrm{L}$ or $\mathrm{D}$ denotes whether they were exposed to diffuse or sunlight simulated light (L), or stored in the dark (D), and finally the B number at the end of the labels represents the particle production batch number. The plotted ratio is the average of $4-8$ particles for each of the samples and the error bars represent 1 sigma standard error.

Despite the variation between samples, the average $\mathrm{F}^{+} / \mathrm{U}^{+}$ratio for the samples stored in low relative humidity air showed no significant decrease compared to the freshlyprepared samples, indicating that little or no ageing occurred after 7 months of storage under these conditions. In addition, single-factor ANOVA analysis $(\alpha=0.05)$ concluded that the $\mathrm{F}^{+} / \mathrm{U}^{+}$variance associated with the different storage times, as well as temperature and lighting conditions in these dry air samples did not exceed the variance expected from random error. 


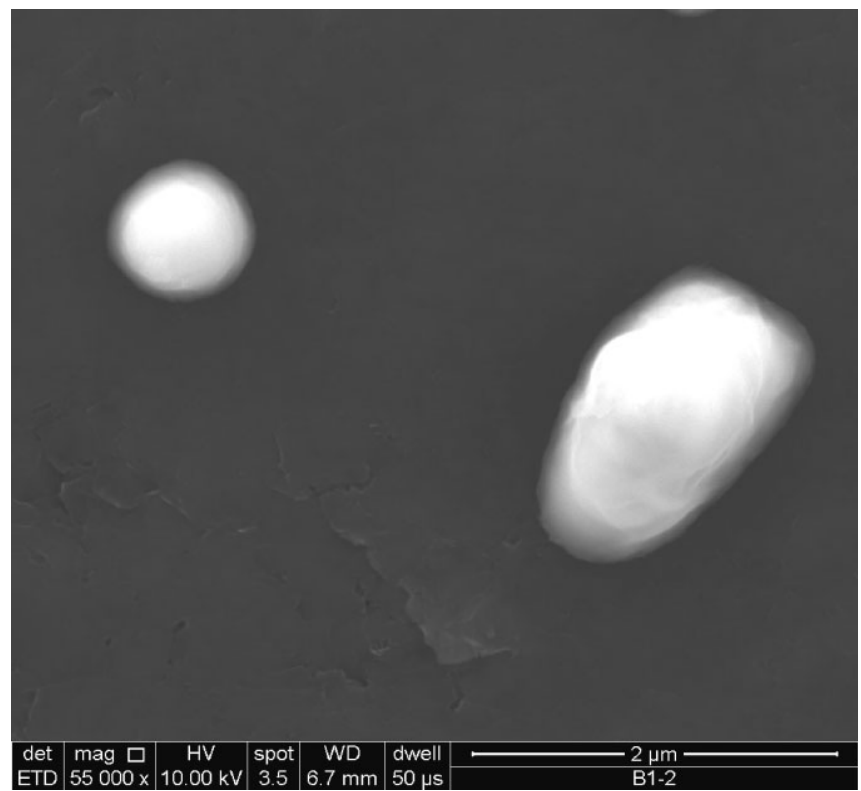

Fig. 5. Scanning electron microscope image of $\mathrm{UO}_{2} \mathrm{~F}_{2}$ particles exposed to $70 \%$ relative humidity.

The exposure to high humidity was found to be the main factor promoting the loss of fluorine in $\mathrm{UO}_{2} \mathrm{~F}_{2}$ particles. The $\mathrm{F}^{+} / \mathrm{U}^{+}$ratio for the samples stored in high humidity air $(76-77 \%)$ at both $25^{\circ} \mathrm{C}$ and $40^{\circ} \mathrm{C}$ varied between one and two orders of magnitude below the values of those samples kept in a dry atmosphere. The count rates for $\mathrm{F}^{+}$started off at around 10-50 cps, compared to several hundred cps for the samples stored in dry air, and were typically reduced to only a few cps after less than 10 cycles. The large spread in the $\mathrm{F}^{+} / \mathrm{U}^{+}$ratio for these samples was partially attributed to changes in particle morphology as a result of the exposure to moisture. $\mathrm{UO}_{2} \mathrm{~F}_{2}$ particles were found to become larger and more round through the uptake of water (Fig. 5), until they eventually turn into liquid solutions covering the planchet's surface, a process also referred to as deliquescence [6]. For samples stored at intermediate relative humidity levels (30\% and $43 \%$ ) for $2-2.5$ months, the decrease in the relative amount of fluorine was much less pronounced.

SEM-EDX analysis was used to determine the variation on the relative amount of fluorine by comparing the peak height of the $\mathrm{U} M_{\alpha}(3.17 \mathrm{keV})$ and $\mathrm{F} K_{\alpha}(0.677 \mathrm{keV})$ peaks. The samples stored in dry air showed considerable variation in the $\mathrm{F} / \mathrm{U}$ ratio $(0.20-0.28)$, while no fluorine was detected in the samples exposed to more than 3 months of relative humidity. The sensitivity of SEM-EDX is several orders of magnitude lower than SIMS (percent level vs. ppb level), and this explains why fluorine was still detected by NanoSIMS and not by SEM-EDX. In addition, the amount of fluorine measured by SEM-EDX was also dependent on the measurement conditions and the analysis time.

\section{Conclusions}

After their preparation in January 2009, a set of $\mathrm{UO}_{2} \mathrm{~F}_{2}$ particles was stored under various environmental conditions to investigate the changes in the relative amount of fluorine.
At LLNL, NanoSIMS analysis of single particles stored in dry air for up to 7 months did not detect a significant decrease in the relative amount of fluorine. The exposure to a high humidity atmosphere however, caused a large decrease in the relative amount of fluorine, with an average $\mathrm{F}^{+} / \mathrm{U}^{+}$ratio of up to 2 orders of magnitude below that of the particles stored in dry air. The total $\mathrm{F}^{+}$counts for these samples were very low and resulted in a large variability in $\mathrm{F}^{+} / \mathrm{U}^{+}$ratios. We therefore plan to carry out experiments at more moderate levels of relative humidity $(30 \%, 40 \%$ and $50 \%$ ) and shorter exposure times (1 day-3 weeks). In spite of this variability, an important conclusion for these initial experiments is that we were able to detect traces of fluorine even after 7 months of storage in a high humidity air, at both $25^{\circ} \mathrm{C}$ and $40^{\circ} \mathrm{C}$. This suggests that the presence of enrichment activities, where fluorine-bearing uranium particles are formed from the release of small amounts of $\mathrm{UF}_{6}$ gas, may be detected through environmental sampling several months after the particles were formed.

Although relative humidity was identified as the main parameter affecting the relative amount of fluorine in $\mathrm{UO}_{2} \mathrm{~F}_{2}$, the effect of UV-light will also be investigated. Planned experiments using micro-Raman spectroscopy will complement these NanoSIMS measurements, and help to determine what chemical bonds are changed by the different storage conditions.

Acknowledgment. This work was performed under the auspices of the US Department of Energy by Lawrence Livermore National Laboratory under contract DE-AC52-07NA27344 and under the auspices of the European Commission, DG Joint Research Centre under Action Sheet 36. The LLNL effort was supported by the DOE/NNSA Office of Dismantlement and Transparency. The analyzed samples were generated by the IRMM expressly for the purpose of this experiment and we have no evidence that fugitive emissions from a uranium enrichment facility would, or would not, appear similar to the samples analyzed. LLNL-CONF-421690.

\section{References}

1. Pickrell, P. W.: Characterization of the solid, airborne materials created by the interaction of $\mathrm{UF}_{6}$ with atmospheric moisture in a contained volume. K/PS-144-DE82015436 (19989.

2. Donohue, D. L.: Strengthening IAEA safeguards through environmental sampling and analysis. J. Alloys Compd. 271-273, 11-18 (1998).

3. Kuhn, E., Fisher, D., Ryjinski, M.: Environmental sampling for IAEA safeguards: a five year review. IAEA-SM-367/10/01 (2001).

4. Ranebo, Y., Hedberg, P. M. L., Whitehouse, M. J., Ingeneri, K., Littman, S.: Improved isotopic SIMS measurements of uranium particles for nuclear safeguards purposes. J. Anal. At Spectrom. 24, 277-287 (2009).

5. Carter, J. A., Hembree, D. M.: Formation and characterization of $\mathrm{UO}_{2} \mathrm{~F}_{2}$ particles as a result of $\mathrm{UF}_{6}$ hydrolysis. Task A.200.3, K/NSP-777 (1998).

6. Kips, R.: Development of uranium reference particles for nuclear safeguards and non-proliferation control. Doctorate Thesis, University of Antwerp (2008).

7. Kips, R., Leenaers, A., Tamborini, G., Betti, M., van den Berghe, S., Wellum, R., Taylor, P. D. P.: Characterization of uranium particles produced by hydrolysis of $\mathrm{UF}_{6}$ using SEM and SIMS. Microsc. Microanal. 13, 156-164 (2007).

8. Kips, R., Crowhurst, J., Kristo, M. J., Hutcheon, I. D., Stefaniak, E.: Micro-Raman spectroscopy of uranium oxyfluoride particulate material for nuclear safeguards. Proceedings of the $51^{\text {st }}$ Annual Meeting of the Institute for Nuclear Materials Management, Baltimore, MD, 11-15 July (2010). 